\title{
Efficient spatial-spectral computation of local planar gravimetric terrain corrections from high-resolution digital elevation models
}

\author{
R. Goyal ${ }^{\oplus}, 1,2$ W.E. Featherstone ${ }^{\oplus}, 1,2$ D. Tsoulis ${ }^{\oplus 3}$ and O. Dikshit ${ }^{\oplus 1}$ \\ ${ }^{1}$ Department of Civil Engineering, Indian Institute of Technology Kanpur, Kanpur 208016, India. E-mail: rupeshg@iitk.ac.in \\ ${ }^{2}$ School of Earth and Planetary Sciences, Curtin University of Technology, GPO Box U1987, Perth, WA 6845, Australia \\ ${ }^{3}$ Department of Geodesy and Surveying, Aristotle University of Thessaloniki, Univ Box 440, 54124 Thessaloniki, Greece
}

Accepted 2020 March 3. Received 2020 February 28; in original form 2019 October 15

\begin{abstract}
S UMMAR Y
Computation of gravimetric terrain corrections (TCs) is a numerical challenge, especially when using very high-resolution (say, $\sim 30 \mathrm{~m}$ or less) digital elevation models (DEMs). TC computations can use spatial or/and spectral techniques: Spatial domain methods are more exact but can be very time-consuming; the discrete/fast Fourier transform (D/FFT) implementation of a binomial expansion is efficient, but fails to achieve a convergent solution for terrain slopes $>45^{\circ}$. We show that this condition must be satisfied for each and every computationroving point pair in the whole integration domain, not just at or near the computation points. A combination of spatial and spectral methods has been advocated by some through dividing the integration domain into inner and outer zones, where the TC is computed from the superposition of analytical mass-prism integration and the D/FFT. However, there remain two unresolved issues with this combined approach: (1) deciding upon a radius that best separates the inner and outer zones and (2) analytical mass-prism integration in the inner zone remains time-consuming, particularly for high-resolution DEMs. This paper provides a solution by proposing: (1) three methods to define the radius separating the inner and outer zones and (2) a numerical solution for near-zone TC computations based on the trapezoidal and Simpson's rules that is sufficiently accurate w.r.t. the exact analytical solution, but which can reduce the computation time by almost 50 per cent.
\end{abstract}

Key words: Gravity anomalies and Earth structure; Fourier analysis; Numerical approximations and analysis; Numerical solutions.

\section{INTRODUCTION}

The gravimetric terrain correction (TC) is computed to account for the gravitational effect of deviations of the Earth's topography from some simplified model for which an exact analytical solution for the gravitational acceleration exists. Arguably the most common simplified model is the Bouguer Plate of thickness equal to the height of the terrain, either relative to some arbitrary height or the geoid depending whether the application is geophysical or geodetic, respectively (cf. Nowell 1999). There are several other geometries that can be used (e.g. Bouguer shell or cap), but which will not be reviewed here. Instead, we only work with planar TCs as these are still efficient for local geodetic (e.g. Majkrakova et al. 2016; Benedek et al. 2018; Dransfield \& Chen 2019; McCubbine et al. 2019; Sobh et al. 2019) and geophysical applications (e.g. Pasteka et al. 2017; Saragih \& Brotopuspito 2018; Zahorec et al. 2019; Ariane Darolle Fofie et al. 2019; Fauzi et al. 2019).

Although, in this paper, we only consider the simplest case of the Bouguer plate by considering the planar TC for localized computations (out to $\sim 100 \mathrm{~km}$ ), but our proposed methods can be adapted and extended to more complicated geometries for the earth model. Our motivation is to seek simultaneously accurate and numerically efficient algorithms for the computation of local TCs for very high-resolution digital height models, such as those derived from the Shuttle Radar Topography Mission (SRTM; Farr et al. 2007), the Advanced Spaceborne Thermal Emission and Reflection Radiometer (ASTER; Meyer et al. 2011) or Multi-Error-Removed Improved-Terrain (MERIT; Yamazaki et al. 2017). We acknowledge that SRTM and ASTER are strictly digital surface models, not digital elevation models (DEMs) like MERIT, but we have used the $1^{\prime \prime} \times 1^{\prime \prime}$ SRTM as if it is a DEM in our numerical experiments. The term DEM will be used throughout this paper for simplicity.

With the generally free availability of high-resolution $\left(1^{\prime \prime} \times 1^{\prime \prime}\right)$ near-global DEMs, the time to compute TCs with space-domain methods can be prohibitive, even using supercomputers. For example, in an area of just $1^{\circ} \times 1^{\circ}$, the number of computation points for a $1^{\prime \prime} \times 1^{\prime \prime}$ DEM (12960 000) is increased eight-fold compared to a $3^{\prime \prime} \times 3^{\prime \prime}$ DEM (1 440 000). Therefore, the use of spectral methods becomes attractive. 
Despite the computational efficiency offered by spectral methods, there are two principal restrictions attached to the use of discrete or fast Fourier transforms (D/FFTs). First, a convergence criterion due to the use of a binomial expansion (e.g. Huang 2012: sect 2.3v) restricts the use of D/FFTs when terrain gradients are $>45^{\circ}$ (e.g. Sideris 1984; Forsberg 1985; Martinec et al. 1996; Sampietro et al. 2016). Secondly, a decision is needed on the truncation limit of the binomial expansion to obtain a convergent TC solution. Some existing strategies to address these restrictions are summarized in the Appendix A1.

From previous TC computations (e.g. Nagy 1966; Forsberg 1984; Tsoulis 1998, 2001; Heck \& Seitz 2007; Tsoulis et al. 2009) the right-rectangular prism is the most commonly recommended elementary mass body for TC computations. The mass-point and mass-line approximations of the mass-prism, while computationally faster, are not sufficiently accurate (Li \& Sideris 1994; Heck \& Seitz 2007). Thus, we only use the mass-prism herein.

All the derivations and computations in this paper follow the planar approximation, which is sufficient for local TCs. Tsoulis et al. (2009) show that by simulating the spherical approximation using 'super-elevation' (Forsberg 1984), the change in the horizontal distance between the computation and roving point at a distance of $100 \mathrm{~km}$ is only $-4 \mathrm{~m}$, so can be neglected. The effect of laterally and radially varying topographic bulk density on TC is also an important aspect. A constant difference of $100 \mathrm{~kg} \mathrm{~m}^{-3}$ in the density can result in an approximate error of $0.037 \times \mathrm{TC}$ (with $\rho=2670 \mathrm{~kg} \mathrm{~m}^{-3}$ ) mGal in TC computation and a $\sim 3.5 \mathrm{mGal}$ error in the Bouguer gravity anomaly for an elevation of $840 \mathrm{~m}$ (Hinze 2003). Since the focus of this study is on the use of high-resolution DEMs, we work only with the constant density assumption. However, it is suggested that for either a precise geodetic application (e.g. Tziavos \& Featherstone 2001; Caratori Tontini et al. 2007; Janák et al. 2017; Yang et al. 2018) or an unambiguous geophysical interpretation (e.g. Uwiduhaye et al. 2018; Saibi et al. 2019; Tschirhart et al. 2019; Rathnayake et al. 2020), a topographic bulk density model (e.g. Blom et al. 2017; Tenzer et al. 2018; Sheng et al. 2019) should be used as an input with the presented methodology and following the formulation provided by Tziavos et al. (1996) and Tziavos \& Sideris (2013).

Subject to the above conditions, we propose a modification to the combined spatial-spectral approach for local planar TC computation under the assumption of a constant topographic density, in which the FFT is applied in the outer zone and mass-prism integration used in the inner zone. We also propose a strategy to divide the inner and outer zones and choose the truncation limit of the binominal expansion in such ways that the D/FFT-driven convergence criterion is satisfied. Additionally, a new faster numerical mass-prism solution is presented based on the trapezoidal and Simpson's rules. Our numerical experiments are conducted in the Himalayas, which hosts among some of the most rugged topographies on Earth.

\section{D/FFT OUTER ZONE TC COMPUTATION}

\subsection{Limitations of existing solutions}

TC computation using the D/FFT was first presented by Parker (1973), but had geodetic limitations in that the computation points must lie above the topography; a case complying more with aeromagnetic and oceanographic than geodetic applications. Sideris (1984) proposed a revised formulation of Parker (1973) to provide TCs on the topographic surface that is more suited to geodetic application. However, a convergence criterion is attached to this method; also see Forsberg (1984, 1985), Sideris (1985), Martinec et al. (1996) and Tsoulis (1998).

The spatial form of the integral for computation of the planar TC that can be expressed as a convolution is (e.g. Sideris 1984)

$T C=G \rho \iint_{E}\left(\frac{1}{l}\left[1-\left[1+\left(\frac{\Delta z}{l}\right)^{2}\right]^{-1 / 2}\right]\right) \mathrm{d} y \mathrm{~d} x$

where $G$ is the universal gravitational constant, $\rho$ is topographic bulk density (herein assumed constant), $l=\sqrt{\left(x_{p}-x_{i}\right)^{2}+\left(y_{p}-y_{i}\right)^{2}}$ is the planar Euclidean distance, $\Delta z=h_{p}-h_{i}$, and $\left(x_{p}, y_{p}, h_{p}\right)$ and $\left(x_{i}, y_{i}, h_{i}\right)$ are the coordinates of computation point and running point, respectively.

Making use of the binomial expansion of $(1+x)^{-1 / 2}$ according to

$(1+x)^{-1 / 2}=1-\frac{1}{2} x+\frac{1.3}{2.4} x^{2}-\frac{1.3 .5}{2.4 .6} x^{3}+\frac{1.3 .5 .7}{2 \cdot 4 \cdot 6.8} x^{4}-\frac{1 \cdot 3 \cdot 5.7 .9}{2 \cdot 4 \cdot 6.8 .10} x^{5}+\frac{1 \cdot 3 \cdot 5 \cdot 7 \cdot 9.11}{2 \cdot 4 \cdot 6 \cdot 8 \cdot 10.12} x^{6}-\ldots$

one can series-expand $\left(1+\left(\frac{\Delta z}{l}\right)^{2}\right)^{-1 / 2}$ in eq. (1) and rearrange terms to give

$T C \approx G \rho \int_{x_{1}}^{x_{2}} \int_{y_{1}}^{y_{2}}\left[\frac{\Delta z^{2}}{2 l^{3}}-\frac{3 \Delta z^{4}}{8 l^{5}}+\frac{5 \Delta z^{6}}{16 l^{7}}-\frac{35 \Delta z^{8}}{128 l^{9}}+\frac{63 \Delta z^{10}}{256 l^{11}}-\frac{231 \Delta z^{12}}{1024 l^{13}}+\ldots.\right] \mathrm{d} x \mathrm{~d} y$

where we abbreviate each as

$T C \approx T C_{1}+T C_{2}+T C_{3}+T C_{4}+T C_{5}+T C_{6}+\ldots$

with each term retains the appropriate sign according to eq. (3). This formulation is a convolution, so can be solved numerically efficiently using the D/FFT (e.g. Schwarz et al. 1990). 


\begin{tabular}{|c|c|c|c|c|c|c|c|c|c|c|}
\hline 20 & 20 & 20 & 20 & 20 & 20 & 20 & 20 & 20 & 20 & 20 \\
\hline 15 & 15 & 15 & 15 & 15 & 15 & 15 & 15 & 15 & 15 & 15 \\
\hline 15 & 10 & 10 & 10 & 10 & 10 & 10 & 10 & 10 & 10 & 15 \\
\hline 15 & 10 & 5 & 5 & 5 & 5 & 5 & 5 & 5 & 10 & 15 \\
\hline 15 & 10 & 5 & 15 & 20 & 25 & 15 & 20 & 5 & 10 & 15 \\
\hline 15 & 10 & 5 & 30 & 30 & 25 & 25 & 35 & 5 & 10 & 15 \\
\hline 15 & 10 & 5 & 25 & 35 & 5 & 5 & 30 & 5 & 10 & 50 \\
\hline 15 & 10 & 5 & 20 & 10 & 20 & 30 & 15 & 5 & 10 & 15 \\
\hline 15 & 10 & 5 & 25 & 20 & 10 & 15 & 20 & 5 & 10 & 15 \\
\hline 15 & 10 & 5 & 5 & 5 & 5 & 5 & 5 & 5 & 10 & 15 \\
\hline 15 & 10 & 10 & 10 & 10 & 10 & 10 & 10 & 10 & 10 & 15 \\
\hline 15 & 15 & 15 & 15 & 15 & 15 & 15 & 15 & 15 & 15 & 15 \\
\hline 20 & 20 & 20 & 20 & 20 & 20 & 20 & 20 & 20 & 20 & 20 \\
\hline
\end{tabular}

Figure 1. Hypothetical DEM with $5 \mathrm{~m}$ resolution. The numbers in the cells represent height. The red cell is the computation point. The yellow cell is one that violates the $<45^{\circ}$ slope condition.

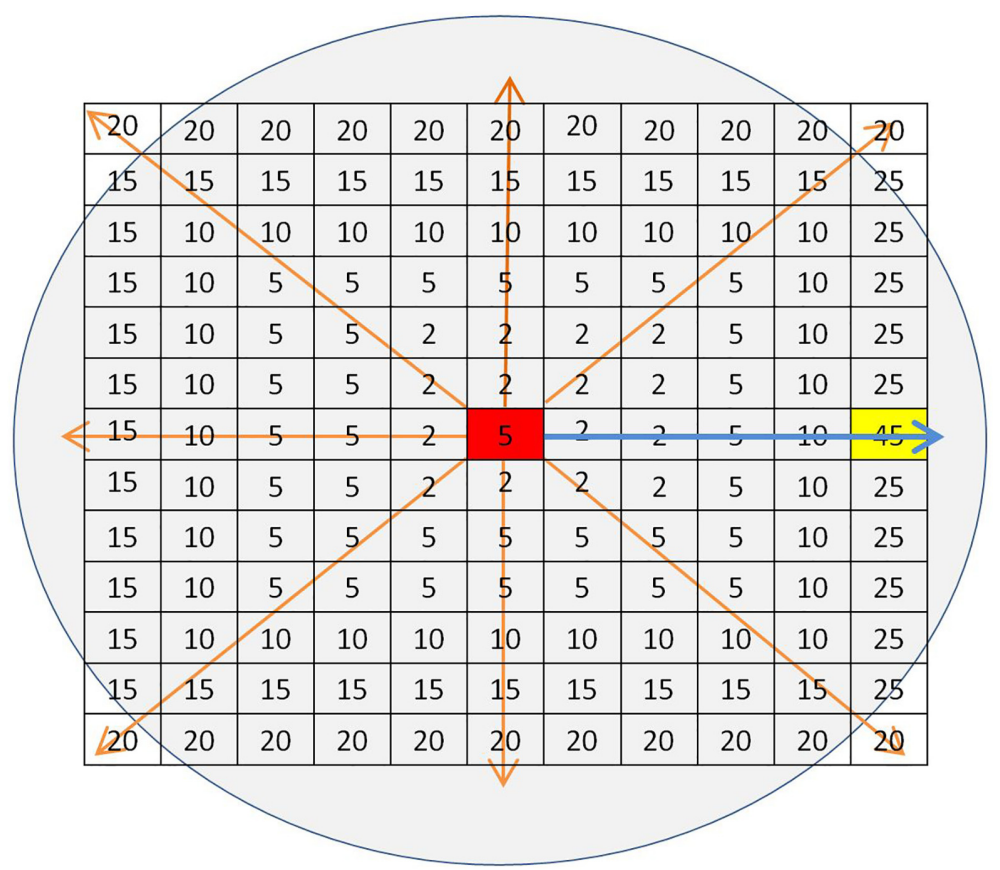

Figure 2. The terrain slope has to be computed in all to identify computation-roving point pairs that are steeper than $45^{\circ}$, otherwise violating the convergence criterion for TC computation.

The convergence criterion for using the binomial expansion in eq. (2) is $-1<x \leq 1$. Therefore, if using eq. (3), the TC can only be computed when the condition

$-1<\left(\frac{\Delta z}{l}\right)^{2} \leq 1 \Rightarrow\left|\frac{\Delta z}{l}\right| \leq 1 \forall l$

is met. This limitation is often referred to as the convergence criterion, which restricts the implementation of eq. (3) to domains having terrain slopes of $<45^{\circ}$. The condition $\forall l$ in eq. (4) must be satisfied for each and every combination of computation and roving points in the whole integration domain. However, in some literature, this condition has been misinterpreted as a requirement that only the slope of the terrain at or immediately surrounding the computation point should not exceed $45^{\circ}$ (e.g. Forsberg 1985; Sideris 1985; Klose \& Ilk 1993; McCubbine et al. 2017; among others).

To exemplify this, consider a hypothetical DEM with a $5 \mathrm{~m}$ spatial resolution, as shown in Fig. 1, where the yellow roving cell is distant from the red computation point but which violates the $<45^{\circ}$ slope condition. Therefore, unless the slope is computed for each and every computation-roving point pair (a time-consuming process as depicted in Fig. 2), and before/during TC computation, numerical convergence 
Table 1. TC values (in $\mu \mathrm{Gal}$ ) after deliberately violating the $<45^{\circ}$ convergence criterion at only one DEM cell. While the effect may appear small here, we could make it arbitrary larger by increasing the cell height by more or by including more cells that violate the $<45^{\circ}$ convergence criterion.

\begin{tabular}{lcc}
\hline TC term & $\begin{array}{c}\text { Unchanged } \\
\text { SRTM DEM }\end{array}$ & $\begin{array}{c}\text { Single cell height } \\
\text { changed to } 6731 \mathrm{~m}\end{array}$ \\
\hline$T C_{1}$ & 331.2 & 332.7 \\
$T C_{2}$ & -2.3 & -3.7 \\
$T C_{3}$ & $3 \times 10^{-2}$ & 1.3 \\
$T C_{4}$ & $-5 \times 10^{-4}$ & -1.3 \\
$T C_{5}$ & $1 \times 10^{-5}$ & 1.4 \\
$T C_{6}$ & $-2 \times 10^{-7}$ & -1.5 \\
$T C_{7}$ & $5 \times 10^{-9}$ & 1.6 \\
$T C_{8}$ & $-1 \times 10^{-10}$ & -1.7 \\
$T C=$ & 328.9 & 327.9 \\
$\Sigma T C_{1} \ldots T C_{8}$ & & \\
\hline
\end{tabular}

will not be assured. However, we do acknowledge that it is plausible that the presence of only a few such roving points may not always provide noticeably divergent $\mathrm{TC}$ results.

To quantify the above statements, TCs were computed up to the eighth order binomial term $\left(T C_{8}\right)$ at the central red cell for a region bounded by $20^{\circ} \mathrm{N}-21^{\circ} \mathrm{N}$, latitude and $81^{\circ} \mathrm{E}-82^{\circ} \mathrm{E}$ longitude using the SRTM V3.0 $1^{\prime \prime} \mathrm{x} 1^{\prime}$ DEM (Farr et al. 2007), with height of the central cell being $531 \mathrm{~m}$. TC values (only from the outer zone beyond an arbitrarily selected $1 \mathrm{~km}$ ) were computed for two scenarios: (1) the unchanged DEM for which all cells satisfy the convergence criterion and (2) after changing the height of only one DEM cell at $l \approx 6 \mathrm{~km}(200 \mathrm{grid}$ cells) from $495 \mathrm{~m}$ to $6731 \mathrm{~m}$ in order to deliberately violate the convergence criterion $(|\Delta z| \leq l)$ at a single point. The results in Table 1 reveal that the presence of even a single point violating the converging criterion causes the solution to diverge.

\subsection{Radius separating the inner and outer zones}

This and the next subsection provide our proposed solutions to satisfy the convergence criterion in the D/FFT method when used in the combined spatial-spectral approach to local planar TC computation. Recall that the D/FFT method is to be used in our so-called outer zone and the mass-prism method is to be used in our so-called inner zone. The motivation behind this combined approach is to achieve computational efficiency while not compromising accuracy. This raises the question of how best to select the integration radius that separates the inner and outer zones.

There is, however, one further choice of integration radius, which we term the bounding radius (BR) that encloses the outer zone [as we define it here]. In the following, we will assume that the BR of the outer zone is sufficiently large so as to capture the entire planar TC, but we do not consider Earth curvature. A common empirical approach is to increment the BR to a distance beyond which the change to the planar TC becomes negligible. We acknowledge that for non-planar geometries, the far/remote zones beyond the BR may not be negligible (cf. Kuhn et al. 2009).

We consider three scenarios to select the radius separating inner and outer zones for the planar TC (Fig. 3). We term them: height-defined separating radius (HSR), exact separating radius (ESR) and optimal separating radius (OSR), as follows.

(i) HSR follows directly from eq. (4), which is a radius that is equal to the magnitude of the maximum height difference in the study area, that is

$H S R=\left|\Delta z_{\max }\right|$

(ii) ESR is calculated from the magnitude of the maximum height difference among all the pairs of computation $(P)$ and rover $(R)$ points in the area bounded by a circle of radius equal to the HSR. This gives the ESR, beyond which the solution will always diverge. Computation of the ESR is time-consuming, especially when the maximum height difference is large, the size of the study area is large, and for a high-resolution DEM. We thus define the ESR as

$E S R=\left|\max \left(\Delta z_{P R}\right)\right| \forall\left\{\begin{array}{l}P\left(x_{P}, y_{P}\right) \subseteq\left(x_{\min } \leq x_{P} \leq x_{\max }, y_{\min } \leq y_{P} \leq y_{\max }\right) \\ \& R(x, y):\left(\left(x-x_{P}\right)^{2}+\left(y-y_{P}\right)^{2}-\Delta z_{\max }^{2} \leq 0\right)\end{array}\right\}$

(iii) OSR is the upper range in the study area. The range is computed by taking the difference between the maximum and the minimum height values in an area around each cell, bounded by a circle of radius equal to the HSR. The upper range is the maximum of these range values in the entire study area. OSR can be computed faster than the ESR because

$O S R=\max \left(\right.$ range $\left._{N}\right) ;$ range $_{N}=\left(\max (z)_{N}-\min (z)_{N}\right) \forall N \equiv P\left(x_{P}, y_{P}\right) \rightarrow R(x, y)$ 


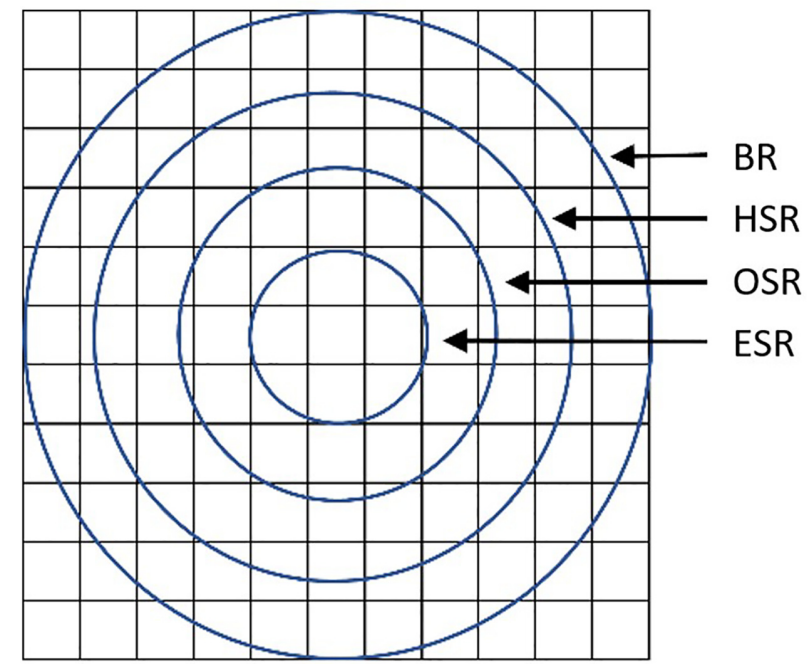

Figure 3. The four integration domains. BR is the bounding radius of the whole integration area. HSR, OSR and ESR are the height-dependent, optimal and exact separating radii, respectively.

Table 2. Details of the five study areas (SA) from SRTM 1" v3.0 (SA5 includes Mount Everest).

\begin{tabular}{lcccccc}
\hline $\begin{array}{l}\text { Study } \\
\text { area }\end{array}$ & $\begin{array}{c}\text { Latitude } \\
\text { bounds }\end{array}$ & $\begin{array}{c}\text { Longitude } \\
\text { bounds }\end{array}$ & Min & Max & Mean & STD \\
\hline SA1 & $29^{\circ} \mathrm{N}-30^{\circ} \mathrm{N}$ & $86^{\circ} \mathrm{E}-87^{\circ} \mathrm{E}$ & 4111 & 6399 & 5161.7 & 371.5 \\
$\mathrm{SA2}$ & $28^{\circ} \mathrm{N}-29^{\circ} \mathrm{N}$ & $86^{\circ} \mathrm{E}-87^{\circ} \mathrm{E}$ & 2535 & 8291 & 5067.4 & 545.3 \\
$\mathrm{SA3}$ & $27^{\circ} \mathrm{N}-28^{\circ} \mathrm{N}$ & $88^{\circ} \mathrm{E}-89^{\circ} \mathrm{E}$ & 182 & 8314 & 3389.0 & 1673.8 \\
SA4 & $27^{\circ} \mathrm{N}-28^{\circ} \mathrm{N}$ & $87^{\circ} \mathrm{E}-88^{\circ} \mathrm{E}$ & 176 & 8250 & 2830.4 & 1586.7 \\
SA5 & $27^{\circ} \mathrm{N}-28^{\circ} \mathrm{N}$ & $86^{\circ} \mathrm{E}-87^{\circ} \mathrm{E}$ & 190 & 8748 & 2572.1 & 1605.9 \\
\hline
\end{tabular}

Table 3. Empirically determined choices of separating radii (in metres).

\begin{tabular}{llll}
\hline Study area & HSR & ESR & OSR \\
\hline SA1 & 2288 & 1642 & 1977 \\
SA2 & 5756 & 3071 & 3354 \\
SA3 & 8132 & 4290 & 5381 \\
SA4 & 8074 & 3637 & 4724 \\
SA5 & 8558 & 4261 & 5456 \\
\hline
\end{tabular}

\subsection{Numerical choice of separating integration radius}

To test the convergence of the TC solution using the proposed choices of separating radii (HSR, ESR and OSR), computations were carried out in five rugged topographies in the Himalayas (Table 2). Table 3 lists the values of the three computed radii for the five study areas using the SRTM 1" V3.0 DEM. A MATLAB ${ }^{\mathrm{TM}}$ subroutine was written to compute the ESR. The focal statistics tool in ArcGIS ${ }^{\mathrm{TM}}$ was used to compute the OSR. Table 3 confirms the relative sizes of the separating radii depicted in Table 3.

\subsection{Effect of separation radius on TC convergence}

To analyse the effect of truncating the binomial expansion of the D/FFT (eq. 3) at different orders, the TC terms are computed up to the tenth order for SA5 (Table 4) using the three different choices of separating radius (Table 3). All computations were performed for outer zones defined by subtracting the three different separating radii (HSR, ESR and OSR) from the BR, arbitrarily selected to be $111320 \mathrm{~m}$ which was driven solely by the size of the data area. No optimization of the BR was attempted because this is only an illustrative example of the convergence.

Recalling from Fig. 3 and Table 3, HSR $>$ OSR $>$ ESR. From Table 4, fewer TC terms are needed to achieve convergence (to $<0.1$ $\mu \mathrm{Gal})$ with the HSR. However, the HSR makes the inner zone larger, which will increase the computation time for the mass-prism integration (Section 3). Conversely, the ESR makes inner zone smallest but needs the largest number of TC terms which will require more computer memory. Also, it takes a longer time to compute the ESR value, especially for a high-resolution DEM.

The OSR offers a compromise that balances the computation of its radius, the number of TC terms required to achieve numerical convergence, and computation time of the inner zone by mass-prisms. Not presented here, this also holds true for the other four study areas in 
Table 4. Descriptive statistics of planar TC values (mGal) in the outer zone up to the tenth order for SA5 with the separating radii of $\mathrm{HSR}=8558 \mathrm{~m}, \mathrm{ESR}=4261 \mathrm{~m}$ and $\mathrm{OSR}=5456 \mathrm{~m}$ and $\mathrm{BR}=111320 \mathrm{~m}$.

\begin{tabular}{|c|c|c|c|c|c|}
\hline $\mathrm{TC}$ term & Separating radius & Min & Max & Mean & STD \\
\hline \multirow[t]{3}{*}{$T C_{1}$} & HSR & 1.237 & 76.047 & 9.195 & 5.393 \\
\hline & ESR & 1.299 & 124.770 & 12.648 & 7.717 \\
\hline & OSR & 1.278 & 107.603 & 11.361 & 6.865 \\
\hline \multirow[t]{3}{*}{$T C_{2}$} & HSR & -2.45 & $-8.71 \times 10^{-4}$ & $-7.07 \times 10^{-2}$ & $1.00 \times 10^{-1}$ \\
\hline & ESR & -11.399 & $-8.95 \times 10^{-4}$ & $-2.01 \times 10^{-1}$ & $3.19 \times 10^{-1}$ \\
\hline & OSR & -7.402 & $-8.8 \times 10^{-4}$ & $-1.40 \times 10^{-1}$ & $2.16 \times 10^{-1}$ \\
\hline \multirow[t]{3}{*}{$T C_{3}$} & HSR & $1.10 \times 10^{-6}$ & $1.73 \times 10^{-1}$ & $1.74 \times 10^{-3}$ & $4.30 \times 10^{-3}$ \\
\hline & ESR & $1.11 \times 10^{-6}$ & 2.299 & $1.19 \times 10^{-2}$ & $3.58 \times 10^{-2}$ \\
\hline & OSR & $1.10 \times 10^{-6}$ & 1.128 & $6.15 \times 10^{-3}$ & $1.75 \times 10^{-2}$ \\
\hline \multirow[t]{3}{*}{$T C_{4}$} & HSR & $-1.69 \times 10^{-6}$ & $-1.84 \times 10^{-9}$ & $-7.84 \times 10^{-5}$ & $2.89 \times 10^{-4}$ \\
\hline & ESR & $-6.50 \times 10^{-1}$ & $-1.85 \times 10^{-9}$ & $-1.32 \times 10^{-3}$ & $6.66 \times 10^{-3}$ \\
\hline & OSR & $-2.27 \times 10^{-1}$ & $-1.84 \times 10^{-9}$ & $-5.00 \times 10^{-4}$ & $2.31 \times 10^{-3}$ \\
\hline \multirow[t]{3}{*}{$T C_{5}$} & HSR & $3.61 \times 10^{-12}$ & $1.92 \times 10^{-3}$ & $4.95 \times 10^{-6}$ & $2.54 \times 10^{-5}$ \\
\hline & ESR & $3.58 \times 10^{-12}$ & $2.30 \times 10^{-1}$ & $2.11 \times 10^{-4}$ & $1.67 \times 10^{-3}$ \\
\hline & OSR & $3.60 \times 10^{-12}$ & $5.32 \times 10^{-2}$ & $5.78 \times 10^{-5}$ & $4.00 \times 10^{-4}$ \\
\hline \multirow[t]{3}{*}{$T C_{6}$} & HSR & $-2.40 \times 10^{-4}$ & $-7.88 \times 10^{-15}$ & $-3.90 \times 10^{-7}$ & $2.66 \times 10^{-6}$ \\
\hline & ESR & $-8.97 \times 10^{-2}$ & $1.51 \times 10^{-13}$ & $-4.34 \times 10^{-5}$ & $5.06 \times 10^{-4}$ \\
\hline & OSR & $-1.36 \times 10^{-2}$ & $-4.70 \times 10^{-15}$ & $-8.45 \times 10^{-6}$ & $8.27 \times 10^{-5}$ \\
\hline \multirow[t]{3}{*}{$T C_{7}$} & HSR & $-7.23 \times 10^{-18}$ & $3.48 \times 10^{-5}$ & $3.60 \times 10^{-8}$ & $3.15 \times 10^{-7}$ \\
\hline & ESR & $-2.52 \times 10^{-9}$ & $3.71 \times 10^{-2}$ & $1.07 \times 10^{-5}$ & $1.74 \times 10^{-4}$ \\
\hline & OSR & $-5.5 \times 10^{-11}$ & $3.76 \times 10^{-3}$ & $1.46 \times 10^{-6}$ & $1.92 \times 10^{-5}$ \\
\hline \multirow[t]{3}{*}{$T C_{8}$} & HSR & $-5.31 \times 10^{-6}$ & $7.60 \times 10^{-13}$ & $-3.74 \times 10^{-9}$ & $4.08 \times 10^{-8}$ \\
\hline & ESR & $-1.61 \times 10^{-6}$ & $9.71 \times 10^{-8}$ & $-3.05 \times 10^{-6}$ & $6.60 \times 10^{-5}$ \\
\hline & OSR & $-1.08 \times 10^{-3}$ & $1.70 \times 10^{-9}$ & $-2.86 \times 10^{-7}$ & $4.88 \times 10^{-6}$ \\
\hline \multirow[t]{3}{*}{$T C_{9}$} & HSR & $-2.97 \times 10^{-12}$ & $8.45 \times 10^{-7}$ & $4.26 \times 10^{-10}$ & $5.67 \times 10^{-9}$ \\
\hline & ESR & $-1.96 \times 10^{-6}$ & $7.24 \times 10^{-3}$ & $9.71 \times 10^{-7}$ & $2.66 \times 10^{-5}$ \\
\hline & OSR & $-1.51 \times 10^{-8}$ & $3.28 \times 10^{-4}$ & $6.17 \times 10^{-8}$ & $1.31 \times 10^{-6}$ \\
\hline \multirow[t]{3}{*}{$T C_{10}$} & HSR & $-1.39 \times 10^{-7}$ & $1.19 \times 10^{-11}$ & $-5.24 \times 10^{-11}$ & $8.32 \times 10^{-10}$ \\
\hline & ESR & $-3.33 \times 10^{-3}$ & $3.50 \times 10^{-6}$ & $-3.37 \times 10^{-7}$ & $1.13 \times 10^{-5}$ \\
\hline & OSR & $-1.02 \times 10^{-4}$ & $1.67 \times 10^{-7}$ & $-1.44 \times 10^{-8}$ & $3.74 \times 10^{-7}$ \\
\hline
\end{tabular}

Table 2. We acknowledge that the exact number of TC terms required will vary depending on the study area, but we have deliberately chosen the extreme example of a $30 \mathrm{~m}$ DEM over Mount Everest, where convergence is achieved using six terms with HSR and nine terms with OSR. Also not presented here, we used the D/FFT to compute TCs from the outer zone for $1982^{\circ} \times 2^{\circ}$ tiles covering parts of India, Pakistan, Sri Lanka, Nepal and China. Convergence was achieved in all cases with the same number of terms.

\section{ANALYTICAL AND NUMERICAL INNER ZONE TC COMPUTATION}

In this section, we begin by stating the formula for analytical mass-prism integration ( $c f$. Banerjee \& Gupta 1977). This is followed by derivation of our proposed numerical integration techniques utilizing the trapezoidal and Simpson's rules for linear integration extended to double integrals. The analytical mass-prism integral of the TC is a volumetric integral solution. The approach suggested here utilises numerical surface integration of the analytical linear solution of TC integral with respect to the z-direction (height).

\subsection{Mass-prism integration}

This method assumes that the cells in the DEM grid define right-rectangular prisms with length and width given by the resolution of the DEM in the $x$ and $y$ directions, respectively. The height of the prism is defined by the height difference of the computation and rover points $(\Delta z)$.

According to Forsberg (1984), the planar TC can be represented as

$T C=G \rho \int_{x_{1}}^{x_{2}} \int_{y_{1}}^{y_{2}} \int_{z_{1}}^{z_{2}} \frac{z}{r^{3}} \mathrm{~d} x \mathrm{~d} y \mathrm{~d} z$

where $r=\sqrt{x^{2}+y^{2}+z^{2}}$ is Euclidean distance (see below). The analytical solution of eq. (8) is

$T C=\left[\left[\left[x\left(\log (y+r)+y \log (x+r)-z \tan ^{-1} \frac{x y}{z r}\right]_{x_{1}}^{x_{2}}\right]_{y_{1}}^{y_{2}}\right]_{z_{1}}^{z_{2}}\right.$ 
which is a simplified, efficient and accurate version (Banerjee \& Gupta 1977; Forsberg 1984) of the solution given by Nagy (1966). Expanding eq. (9) with respect to its limits, gives

$$
\left.\begin{array}{rl}
T C= & x_{2} \log \left(y_{2}+r_{222}\right)-x_{2} \log \left(y_{2}+r_{221}\right)-x_{2} \log \left(y_{1}+r_{212}\right)+x_{2} \log \left(y_{1}+r_{211}\right) \\
& -x_{1} \log \left(y_{2}+r_{122}\right)-x_{1} \log \left(y_{2}+r_{121}\right)-x_{1} \log \left(y_{1}+r_{112}\right)+x_{1} \log \left(y_{1}+r_{111}\right) \\
& +y_{2} \log \left(x_{2}+r_{222}\right)-y_{2} \log \left(x_{2}+r_{221}\right)-y_{2} \log \left(x_{1}+r_{122}\right)+y_{2} \log \left(x_{1}+r_{121}\right) \\
& -y_{1} \log \left(x_{2}+r_{212}\right)+y_{1} \log \left(x_{2}+r_{211}\right)+y_{1} \log \left(x_{1}+r_{112}\right)-y_{1} \log \left(x_{1}+r_{111}\right) \\
& -z_{2} \tan ^{-1}\left(\frac{x_{2} y_{2}}{z_{2} r_{222}}\right)+z_{2} \tan ^{-1}\left(\frac{x_{2} y_{1}}{z_{2} r_{212}}\right)+z_{2} \tan ^{-1}\left(\frac{x_{1} y_{2}}{z_{2} r_{122}}\right)-z_{2} \tan ^{-1}\left(\frac{x_{1} y_{1}}{z_{2} r_{112}}\right) \\
& +z_{1} \tan ^{-1}\left(\frac{x_{2} y_{2}}{z_{1} r_{221}}\right)-z_{1} \tan ^{-1}\left(\frac{x_{2} y_{1}}{z_{1} r_{211}}\right)-z_{1} \tan ^{-1}\left(\frac{x_{1} y_{2}}{z_{1} r_{121}}\right)+z_{1} \tan ^{-1}\left(\frac{x_{1} y_{1}}{z_{1} r_{111}}\right)
\end{array}\right\},
$$

where $z_{1}=0 ; z_{2}=h_{p}-h_{i} ; h_{p}$ is the height of the computation point and $h_{i}$ the height of the roving point. $x_{1}, x_{2}, y_{1}, y_{2}$ are the planar coordinates of a prism assuming the computation point to be at the origin of the planar coordinate system. The order of subscripts of $r=\sqrt{x^{2}+y^{2}+z^{2}}$ represents the order of coordinates $(x, y, z)$ and the subscript value represents the lower or upper bound of that coordinate. For example, $r_{122}$ represents $\sqrt{x_{1}^{2}+y_{2}^{2}+z_{2}^{2}}$, etc.

Rearranging the terms in eq. (10), the analytical formula for the TC using right-rectangular mass prisms (TCM) is

$$
\begin{aligned}
& T C M=x_{2}\left[\log \left(\frac{\left(y_{2}+r_{222}\right)\left(y_{1}+r_{211}\right)}{\left(y_{2}+r_{221}\right)\left(y_{1}+r_{212}\right)}\right)\right]-x_{1}\left[\log \left(\frac{\left(y_{2}+r_{122}\right)\left(y_{1}+r_{111}\right)}{\left(y_{2}+r_{121}\right)\left(y_{1}+r_{112}\right)}\right)\right] \\
& +y_{2}\left[\log \left(\frac{\left(x_{2}+r_{222}\right)\left(x_{1}+r_{121}\right)}{\left(x_{2}+r_{221}\right)\left(x_{1}+r_{122}\right)}\right)\right]-y_{1}\left[\log \left(\frac{\left(x_{2}+r_{212}\right)\left(x_{1}+r_{111}\right)}{\left(x_{2}+r_{211}\right)\left(x_{1}+r_{112}\right)}\right)\right] \\
& \left.-z_{2}\left[\tan ^{-1}\left(\frac{x_{2} y_{2}}{z_{2} r_{222}}\right)-\tan ^{-1}\left(\frac{x_{2} y_{1}}{z_{2} r_{212}}\right)-\tan ^{-1}\left(\frac{x_{1} y_{2}}{z_{2} r_{122}}\right)+\tan ^{-1}\left(\frac{x_{1} y_{1}}{z_{2} r_{112}}\right)\right]\right\} \\
& \left.+z 1\left[\tan ^{-1}\left(\frac{x_{2} y_{2}}{z_{1} r_{221}}\right)-\tan ^{-1}\left(\frac{x_{2} y_{1}}{z_{1} r_{211}}\right)-\tan ^{-1}\left(\frac{x_{1} y_{2}}{z_{1} r_{121}}\right)+\tan ^{-1}\left(\frac{x_{1} y_{1}}{z_{1} r_{111}}\right)\right]\right]
\end{aligned}
$$

\subsection{Trapezoidal rule integration}

Solving the TC integral (eq. 8) with respect to ' $z$ ' is convenient compared to ' $x$ ' and ' $y$ '. Therefore, in this method, the trapezoidal rule for single integration is extended to double integration for solving the surface integral achieved after analytical linear integration of eq. (8) with respect to ' $\mathrm{z}$ '. According to the trapezoidal rule for single integration with $n=2$ subintervals (refer to the end of Section 3.4 for further discussion), we have

$$
\int_{a}^{b} f(x) d x \approx \frac{g}{2}\left[f(a)+2 f\left(\frac{a+b}{2}\right)+f(b)\right], g=\frac{b-a}{n} .
$$

Extending eq. (12) to solve double integration gives

$$
\left.\begin{array}{rl}
\int_{a}^{b}\left(\int_{c}^{\mathrm{d}} f(x, y) \mathrm{d} y\right) \mathrm{d} x & \approx \int_{a}^{b}\left(\frac{(d-c)}{4}\left[f(x, c)+2 f\left(x, \frac{c+d}{2}\right)+f(x, d)\right]\right) \mathrm{d} x \\
& =\int_{a}^{b}\left(\frac{d-c}{4}\right) f(x, c) \mathrm{d} x+\int_{a}^{b} 2\left(\frac{d-c}{4}\right) f\left(x, \frac{c+d}{2}\right) \mathrm{d} x+\int_{a}^{b}\left(\frac{d-c}{4}\right) f(x, d) \mathrm{d} x \\
& =T T 1+T T 2+T T 3
\end{array}\right\},
$$

where $T T 1, T T 2, T T 3$ represent the three integral terms in eq. (13). By applying the trapezoidal rule for $n=2$ to these three terms individually, we get

$$
\left.\begin{array}{l}
T T 1=\left(\frac{b-a}{4}\right)\left(\frac{d-c}{4}\right)\left[f(a, c)+2 f\left(a, \frac{c+d}{2}\right)+f(a, d)\right] \\
T T 2=2\left(\frac{b-a}{4}\right)\left(\frac{d-c}{4}\right)\left[f\left(\frac{a+b}{2}, c\right)+2 f\left(\frac{a+b}{2}, \frac{c+d}{2}\right)+f\left(\frac{a+b}{2}, d\right)\right] \\
T T 3=\left(\frac{b-a}{4}\right)\left(\frac{d-c}{4}\right)\left[f(b, c)+2 f\left(b, \frac{c+d}{2}\right)+f(b, d)\right]
\end{array}\right\} .
$$

The analytical linear integral solution of the TC with respect to ' $z$ ' can be written as

$$
\left.\begin{array}{rl}
T C & =G \rho\left[\iint_{E}^{z_{2}=h_{p}-h_{i}} \int_{z_{1}=0}^{z} \frac{z}{r^{3}} \mathrm{~d} z \mathrm{~d} y \mathrm{~d} x\right] \\
& =G \rho\left[\int_{x_{1}}^{x_{2}} \int_{y_{1}}^{y_{2}}\left(\frac{1}{r\left(x, y, z_{1}\right)}-\frac{1}{r\left(x, y, z_{2}\right)}\right) \mathrm{d} y \mathrm{~d} x\right]
\end{array}\right\} .
$$


Table 5. Geographical bounds of the study areas and their respective height statistics.

\begin{tabular}{lcccccc}
\hline $\begin{array}{l}\text { Study } \\
\text { area }\end{array}$ & $\begin{array}{c}\text { Latitude } \\
\text { bound }\end{array}$ & Longitude & \multicolumn{4}{c}{ SRTM heights $(\mathrm{m})$} \\
bound & Min & Max & Mean & STD \\
\hline SAA & $19.25^{\circ} \mathrm{N}-19.75^{\circ} \mathrm{N}$ & $73.25^{\circ} \mathrm{E}-73.75^{\circ} \mathrm{E}$ & 2 & 1537 & 299 & 264 \\
SAB & $26.25^{\circ} \mathrm{N}-26.75^{\circ} \mathrm{N}$ & $80.25^{\circ} \mathrm{E}-80.75^{\circ} \mathrm{E}$ & 94 & 155 & 123 & 5 \\
$\mathrm{SAC}$ & $28.25^{\circ} \mathrm{N}-28.75^{\circ} \mathrm{N}$ & $83.25^{\circ} \mathrm{E}-83.75^{\circ} \mathrm{E}$ & 723 & 8141 & 2976 & 1334 \\
\hline
\end{tabular}

Using the following substitutions in eq. (14)

$$
\left.\begin{array}{l}
a=x_{1}, b=x_{2}, c=y_{1}, d=y_{2} \\
b-a=x_{2}-x_{1}=\Delta x, c-d=y_{2}-y_{1}=\Delta y \\
z_{1}=0, z_{2}=h_{p}-h_{i}=\Delta z \\
\frac{a+b}{2}=\frac{x_{1}+x_{2}}{2}=\bar{x}, \frac{c+d}{2}=\frac{y_{1}+y_{2}}{2}=\bar{y}
\end{array}\right\}
$$

and rearranging terms, the TC with the trapezoidal rule (TCT) can be calculated as

$$
\begin{aligned}
T C T= & G \rho\left\{\left(\frac{\Delta x}{4}\right)\left(\frac{\Delta y}{4}\right)\left[\left(\frac{1}{r\left(x_{1}, y_{1}\right)}-\frac{1}{r\left(x_{1}, y_{1}, \Delta z\right)}\right)+2\left(\frac{1}{r\left(x_{1}, \bar{y}\right)}-\frac{1}{r\left(x_{1}, \bar{y}, \Delta z\right)}\right)+\left(\frac{1}{r\left(x_{1}, y_{2}\right)}-\frac{1}{r\left(x_{1}, y_{2}, \Delta z\right)}\right)\right]\right. \\
& +2\left(\frac{\Delta x}{4}\right)\left(\frac{\Delta y}{4}\right)\left[\left(\frac{1}{r\left(\bar{x}, y_{1}\right)}-\frac{1}{r\left(\bar{x}, y_{1}, \Delta z\right)}\right)+2\left(\frac{1}{r(\bar{x}, \bar{y})}-\frac{1}{r(\bar{x}, \bar{y}, \Delta z)}\right)+\left(\frac{1}{r\left(\bar{x}, y_{2}\right)}-\frac{1}{r\left(\bar{x}, y_{2}, \Delta z\right)}\right)\right] \\
& \left.+\left(\frac{\Delta x}{4}\right)\left(\frac{\Delta y}{4}\right)\left[\left(\frac{1}{r\left(x_{2}, y_{1}\right)}-\frac{1}{r\left(x_{2}, y_{1}, \Delta z\right)}\right)+2\left(\frac{1}{r\left(x_{2}, \bar{y}\right)}-\frac{1}{r\left(x_{2}, \bar{y}, \Delta z\right)}\right)+\left(\frac{1}{r\left(x_{2}, y_{2}\right)}-\frac{1}{r\left(x_{2}, y_{2}, \Delta z\right)}\right)\right]\right\}
\end{aligned} .
$$

\subsection{Simpson's rule integration}

According to Simpson's rule for single integration, again with $n=2$ subintervals (again refer to the end of Section 3.4), we have

$$
\int_{a}^{b} f(x) \mathrm{d} x \approx \frac{t}{3}\left[f(a)+4 f\left(\frac{a+b}{2}\right)+f(b)\right], t=\frac{b-a}{n} .
$$

For double integration, eq. (17) takes the form

$$
\left.\begin{array}{rl}
\int_{a}^{b}\left(\int_{c}^{d} f(x, y) \mathrm{d} y\right) \mathrm{d} x & \approx \int_{a}^{b}\left(\frac{(d-c)}{6}\left[f(x, c)+4 f\left(x, \frac{c+d}{2}\right)+f(x, d)\right]\right) \mathrm{d} x \\
& =\int_{a}^{b}\left(\frac{d-c}{6}\right) f(x, c) \mathrm{d} x+\int_{a}^{b} 4\left(\frac{d-c}{6}\right) f\left(x, \frac{c+d}{2}\right) \mathrm{d} x+\int_{a}^{b}\left(\frac{d-c}{6}\right) f(x, d) \mathrm{d} x \\
& =S T 1+S T 2+S T 3
\end{array}\right\},
$$

where $S T$ 1, ST2, ST 3 represent the three integral terms in eq. (19). By applying Simpson's rule to the three terms individually, we get

$$
\left.\begin{array}{l}
S T 1=\left(\frac{b-a}{6}\right)\left(\frac{d-c}{6}\right)\left[f(a, c)+4 f\left(a, \frac{c+d}{2}\right)+f(a, d)\right] \\
S T 2=4\left(\frac{b-a}{6}\right)\left(\frac{d-c}{6}\right)\left[f\left(\frac{a+b}{2}, c\right)+4 f\left(\frac{a+b}{2}, \frac{c+d}{2}\right)+f\left(\frac{a+b}{2}, d\right)\right] \\
S T 3=\left(\frac{b-a}{6}\right)\left(\frac{d-c}{6}\right)\left[f(b, c)+4 f\left(b, \frac{c+d}{2}\right)+f(b, d)\right]
\end{array}\right\} .
$$

The numerical solution of TC using Simpson's rule (TCS) is obtained using the substitutions from eq. (16) in eq. (20) to yield

$$
\begin{aligned}
T C S= & G \rho\left\{\left(\frac{\Delta x}{6}\right)\left(\frac{\Delta y}{6}\right)\left[\left(\frac{1}{r\left(x_{1}, y_{1}\right)}-\frac{1}{r\left(x_{1}, y_{1}, \Delta z\right)}\right)+4\left(\frac{1}{r\left(x_{1}, \bar{y}\right)}-\frac{1}{r\left(x_{1}, \bar{y}, \Delta z\right)}\right)+\left(\frac{1}{r\left(x_{1}, y_{2}\right)}-\frac{1}{r\left(x_{1}, y_{2}, \Delta z\right)}\right)\right]\right\} \\
& +4\left(\frac{\Delta x}{6}\right)\left(\frac{\Delta y}{6}\right)\left[\left(\frac{1}{r\left(\bar{x}, y_{1}\right)}-\frac{1}{r\left(\bar{x}, y_{1}, \Delta z\right)}\right)+4\left(\frac{1}{r(\bar{x}, \bar{y})}-\frac{1}{r(\bar{x}, \bar{y}, \Delta z)}\right)+\left(\frac{1}{r\left(\bar{x}, y_{2}\right)}-\frac{1}{r\left(\bar{x}, y_{2}, \Delta z\right)}\right)\right] \\
& \left.+\left(\frac{\Delta x}{6}\right)\left(\frac{\Delta y}{6}\right)\left[\left(\frac{1}{r\left(x_{2}, y_{1}\right)}-\frac{1}{r\left(x_{2}, y_{1}, \Delta z\right)}\right)+4\left(\frac{1}{r\left(x_{2}, \bar{y}\right)}-\frac{1}{r\left(x_{2}, \bar{y}, \Delta z\right)}\right)+\left(\frac{1}{r\left(x_{2}, y_{2}\right)}-\frac{1}{r\left(x_{2}, y_{2}, \Delta z\right)}\right)\right]\right\} .
\end{aligned}
$$

\subsection{Numerical analyses}

The proposed numerical methods for mass-prism integration are tested on three different smaller study areas (that exhibit varying terrain roughness) again using the SRTM 1" v3.0 DEM (Table 5). Mass-prism TC values were computed with the separating radius defined by the OSR computed individually for each study area (Table 6). Computations were performed using MATLAB ${ }^{\text {TM }}$ parallelization on 18 cores of an Intel@ Xeon $R$ E7-8870 v3@2.10 GHz CPU having 251 GB of RAM. The statistics and time required for TC computation using the analytical (TCM) and numerical (TCT and TCS) methods for the three study areas are given in Table 6. The statistics of the difference between the TC values computed using analytical and numerical methods are given in Table 7.

Although there is no significant variation among the overall TC statistics (Table 6) using the three different methods, TCT provides comparatively better results compared to the TCM than TCS (Table 7). An important observation from Table 6 is that the time required for 
Table 6. Statistics of 1"x1' TC values computed using the three methods (equations 11, 17 and 21) for three different study areas [TCs are in $\mathrm{mGal}$ and $\mathrm{CPU}$ time is rounded to the nearest second].

\begin{tabular}{lccccccrrr}
\hline & \multicolumn{3}{c}{ SAA, OSR $=1141 \mathrm{~m}$} & \multicolumn{3}{c}{$\mathrm{SAB}, \mathrm{OSR}=46 \mathrm{~m}$} & \multicolumn{3}{c}{ SAC, OSR $=6078 \mathrm{~m}$} \\
& $T C M$ & $T C T$ & $T C S$ & $T C M$ & $T C T$ & $T C S$ & $T C M$ & $T C T$ & $T C S$ \\
\hline Min & 0.000 & 0.000 & 0.000 & 0.000 & 0.000 & 0.000 & 4.542 & 4.546 & 4.531 \\
Max & 22.779 & 22.713 & 22.627 & 1.032 & 0.897 & 0.839 & 126.646 & 126.623 & 126.563 \\
Mean & 0.722 & 0.720 & 0.711 & 0.003 & 0.003 & 0.002 & 22.180 & 22.162 & 22.110 \\
STD & 1.487 & 1.483 & 1.472 & 0.005 & 0.004 & 0.004 & 11.898 & 11.892 & 11.882 \\
RMS & 1.653 & 1.649 & 1.635 & 0.006 & 0.005 & 0.005 & 25.170 & 25.151 & 25.101 \\
Time & 428 & 201 & 199 & 38 & 12 & 12 & 37746 & 17539 & 17481 \\
\hline
\end{tabular}

Table 7. Statistics of the difference between TC values computed using analytical (TCM) and numerical (TCS and TCT) methods [units in mGal].

\begin{tabular}{lcccccc}
\hline & \multicolumn{2}{c}{ SAA } & \multicolumn{2}{c}{ SAB } & \multicolumn{2}{c}{ SAC } \\
& $T C M-T C T$ & TCM-TCS & TCM-TCT & TCM-TCS & TCM-TCT & TCM-TCS \\
\hline Min & -0.031 & 0.000 & -0.006 & 0.000 & -0.036 & 0.000 \\
Max & 0.136 & 0.246 & 0.135 & 0.192 & 0.144 & 0.248 \\
Mean & 0.002 & 0.011 & 0.001 & 0.001 & 0.017 & 0.070 \\
STD & 0.006 & 0.019 & 0.001 & 0.001 & 0.022 & 0.040 \\
RMS & 0.007 & 0.022 & 0.001 & 0.002 & 0.028 & 0.080 \\
\hline
\end{tabular}

TC computation using our proposed methods (both TCT and TCS) is almost half of what is required for analytical TCM. Table 7 confirms that the TCT and TCS are consistent with respect to (i) the ruggedness of topography (cf. Table 5) and (ii) the size of the OSR ( $c f$. Table 6).

In the trapezoidal and Simpson's rules of integration (TCT and TCS), the numerical results can be improved by increasing the number of subintervals, but at some computational cost. TCT and TCS were rederived using a combination of $n=2$ subintervals for the inner limit and $n=4$ for the outer limit. This was done because only an even number of subintervals can be used in Simpson's rule. The derived formulas were tested on SAC. Not significant, but an improvement was observed in the results versus TCM. However, time taken for the computations became equivalent to the TCM.

\section{CONCLUDING REMARKS}

The free availability of high-resolution ( $\sim 30$ m or less) near-global digital elevation models poses a substantial challenge for the numerical computation of gravimetric TCs. One computationally attractive option is to divide the integration domain into inner and outer zones, where spectral methods are used in the outer zone and analytical or discretized numerical mass-prism integration is used in the inner zone. However, this spatial-spectral combination suffers from a few unresolved issues: (1) the need to ascertain that the D/FFT implementation of the binomial expansion of the TC formula (eq. 3) provides a numerically convergent solution, (2) the appropriate separation radius between the inner and outer zones is selected so as to achieve an accurate and convergent result while profiting computationally from a smaller inner zone and (3) the analytical mass-prism integration method (eq. 11) is very time consuming, even on supercomputers.

Our principal conclusions are:

(i) The D/FFT implementation of the binomial expansion of the TC integral is only convergent iff the terrain gradients are $<45^{\circ}$ for each and every computation-roving point pair in the integration domain. This condition appears to have been overlooked in some previous implementations of the D/FFT method, where it is only considered at or near the computation point.

(ii) The radius separating the inner zone, where mass-prism integration is conducted, and the outer zone, where D/FFT integration is conducted, can be selected so as to achieve a balance among numerical convergence, accuracy and efficient computation time. Our so-called optimal separation radius (OSR) is given by eq. (7) and depends on the range of height differences in the whole integration domain. When using the binomial expansion of the TC (eq. 3) in areas of very rugged terrain and for high-resolution DEMs, higher order terms cannot be neglected ( $c f$. Tables 1 and 4).

(iii) The analytical solution to the gravitational attraction of a right-rectangular prism in the inner zone can be replaced by numerical integration based on the trapezoidal and Simpson's rules extended to double integrals. Numerical experiments over Mount Everest on a 1"x1" grid show all the mass-prism TC solutions to be commensurate but can be achieved in roughly half the computation time when two integration steps are used in the trapezoidal and Simpson's methods.

\section{ACKNOWLEDGEMENTS}

We would like to thank Dr Jack McCubbine, Geoscience Australia, for publicly sharing his FFTTC.m MATLAB ${ }^{\text {TM }}$ routine (https://uk.m athworks.com/matlabcentral/profile/authors/4329165-jack). Dr Sten Claessens, Curtin University of Technology and Prof Balasubramania Nagarajan, Indian Institute of Technology Kanpur, are also thanked for providing helpful discussions. Will Featherstone thanks the Indian 
Scheme for Promotion of Academic and Research Collaboration (SPARC) programme for funding his visit to India. We thank the editor (Prof Bert Vermeersen) and two reviewers (Dr Robert Tenzer and one anonymous) for their extraordinarily prompt and very constructive reviews of this paper.

\section{REFERENCES}

Banerjee, B. \& Gupta, S.P.D., 1977. Gravitational attraction of a rectangular parallelepiped, Geophysics, 42(5), 1053-1055.

Benedek, J., Papp, G. \& Kalmár, J., 2018. Generalization techniques to reduce the number of volume elements for terrain effect calculations in fully analytical gravitational modelling, J. Geod., 92, 361-381.

Blom, N., Boehm, C. \& Fichtner, A., 2017. Synthetic inversions for density using seismic and gravity data, Geophys. J. Int., 209(2), 1204-1220.

Capponi, M., Mansi, A.H. \& Sampietro, D., 2018. Improving the computation of the gravitational terrain effect close to ground stations in the GTE software, Stud. Geophys. Geod., 62(2), 206-222.

Caratori Tontini, F., Graziano, F., Cocchi, L., Carmisciano, C. \& Stefanelli, P., 2007. Determining the optimal Bouguer density for a gravity data set: implications for the isostatic setting of the Mediterranean Sea, Geophys. J. Int., 169(2), 380-388.

Dransfield, M.H. \& Chen, T., 2019. Heli-borne gravity gradiometry in rugged terrain, Geophys. Prospect., 67(6), 1626-1636.

Farr, T.G. et al., 2007. The shuttle radar topography mission, Rev. Geophys., 45(2), RG2004. doi:10.1029/2005RG000183

Fauzi, F.A., Arifin, M.H., Basori, M.B.I., Mohd Noh, K.A. \& Umor, M.R., 2019. Application of gravity survey for tin exploration at bongsu granite, Kulim, Kedah, Malaysia, Sains Malaysiana, 48(11), 2503-2509.

Fofie, K.A.D., Koumetio, F., Kenfack, J.V. \& Yemele, D., 2019. Lineament characteristics using gravity data in the Garoua Zone, North Cameroon: natural risks implications, Earth planet. Phys., 3(1), 33-44.

Forsberg, R., 1984, Study of terrain reductions, density anomalies and geophysical inversion methods in gravity field modelling. Report 355, Department of Geodetic Science and Surveying, The Ohio State University, Columbus, USA.

Forsberg, R., 1985. Gravity field terrain effect computations by FFT, Bulletin Géodésique, 59(4), 342-360.

Gomez, M.E., Bagu, D.R., Del Cogliano, D. \& Perdomo, R.A., 2013. Evaluation of terrain corrections through FFT and classical integration in two selected areas of the Andes and their impact on geoidal heights, Boletim de Ciências Geodésicas, 19(3), 407-419.

Harrison, J.C. \& Dickinson, M., 1991. Practical considerations in the use of FFT methods for computing terrain effects, in Determination of the Geoid. International Association of Geodesy Symposia, Vol 106, pp. 119128, eds Rapp, R.H. \& Sansò, F., Springer. https://doi.org/10.1007/9781-4612-3104-2_14

Heck, B. \& Seitz, K., 2007. A comparison of the tesseroid, prism and pointmass approaches for mass reductions in gravity field modelling, J. Geod., 81(2), 121-136.

Hinze, W.J., 2003. Bouguer reduction density, why 2.67?, Geophysics, 68(5), $1559-1560$.

Huang, O., 2012. Terrain corrections for gravity gradiometry. Report 500, Department of Geodetic Science and Surveying, The Ohio State University, Columbus, USA.

Janák, J., Vańiček, P., Foroughi, I., Kingdon, R., Sheng, M.B. \& Santos, M.C., 2017. Computation of precise geoid model of Auvergne using current UNB Stokes-Helmert's approach, Contrib. Geophys. Geod., 47(3), 201-229.

Kirby, J. \& Featherstone, W., 2002. High-resolution grids of gravimetric terrain correction and complete Bouguer corrections over Australia, Explor. Geophys., 33(4), 161-165.

Kirby, J.F. \& Featherstone, W.E., 1999. Terrain correcting Australian gravity observations using the national digital elevation model and the fast Fourier transform, Aust. J. Earth Sci., 46(4), 555-562.

Kirby, J.F. \& Featherstone, W.E., 2001. Anomalously large gradients in version 1 of the "GEODATA 9 SECOND" Digital Elevation Model of Australia, and their effects on gravimetric terrain corrections, Cartography, 30(1), 1-10.
Klose, U. \& Ilk, K., 1993. A solution to the singularity problem occurring in the terrain correction formula, Manuscripta Geodaetica, 18(5), 263-279.

Kuhn, M., Featherstone, W.E. \& Kirby, J.F., 2009. Complete spherical Bouguer gravity anomalies over Australia, Aust. J. Earth Sci., 56(2), 213-223.

Li, Y.C. \& Sideris, M.G., 1994. Improved gravimetric terrain corrections, Geophys. J. Int., 119(3), 740-752.

Majkráková, M., Papčo, J., Zahorec, P., Droščák, B., Mikuška, J. \& Marušiak, I., 2016. An analysis of methods for gravity determination and their utilization for the calculation of geopotential numbers in the Slovak national levelling network, Contrib. Geophys. Geod., 46, 179-202.

Martinec, Z., Vaníček, P., Mainville, A. \& Véronneau, M., 1996. Evaluation of topographical effects in precise geoid computation from densely sampled heights, J. Geod., 70(11), 746-754.

McCubbine, J.C., Featherstone, W.E. \& Brown, N.J., 2019. Error propagation for the Molodensky G1 term. J. Geod. 93, 889-898.

McCubbine, J.C., Featherstone, W.E. \& Kirby, J.F., 2017. Fast-Fourier-based error propagation for the gravimetric terrain correction, Geophysics, 82(4), G71-G76.

Meyer, D. et al., 2011. ASTER Global Digital Elevation Model Version 2- Summary of Validation Results. Available at: https://ssl.jspacesystems.or.jp/ersdac/GDEM/ver2Validation/Summa ry_GDEM2_validation_report_final.pdf.

Nagy, D., 1966. The prism method for terrain corrections using digital computers, Pure appl. Geophys., 63(1), 31-39.

Nowell, D.A., 1999. Gravity terrain corrections - an overview, J. appl. Geophys., 42(2), 117-134.

Parker, R.L., 1973. The rapid calculation of potential anomalies, Geophys. J. Int., 31(4), 447-455.

Pašteka, R. et al., 2017. High resolution Slovak Bouguer gravity anomaly map and its enhanced derivative transformations: new possibilities for interpretation of anomalous gravity fields, Contrib. Geophys. Geod., 47(2), $81-94$.

Rathnayake, S., Tenzer, R., Pitoňák, M. \& Novák, P., 2020. Effect of the lateral topographic density distribution on interpretational properties of Bouguer gravity maps, Geophys. J. Int., 220(2), 892-909.

Saibi, H., Gabr, A. \& Mohamed, F.S., 2019. Subsurface structural mapping using gravity data of Al-Ain region, Abu Dhabi Emirate, United Arab Emirates, Geophys. J. Int., 216(2), 1201-1213.

Sampietro, D., Capponi, M., Triglione, D., Mansi, A.H., Marchetti, P. \& Sansò, F., 2016. GTE: a new software for gravitational terrain effect computation: theory and performances, Pure appl. Geophys., 173(7), 24352453.

Saragih, R.D. \& Brotopuspito, K.S., 2018. Delineation of the Sumatra fault in the central part of west sumatra based on gravity method, J. Phys. Conf. Ser., 1011, 012024 doi:10.1088/1742-6596/1011/1/012024.

Schwarz, K.-P., Sideris, M.G. \& Forsberg, R., 1990. The use of FFT techniques in physical geodesy, Geophys. J. Int., 100(3), 485-514.

Sheng, M.B., Shaw, C., Vaníček, P., Kingdon, R.W., Santos, M. \& Foroughi, I., 2019. Formulation and validation of a global laterally varying topographical density model, Tectonophysics, 762, 45-60.

Sideris, M.G., 1984, Computation of gravimetric terrain corrections using fast Fourier transform techniques, UCSE Report 20007, University of Calgary, Canada.

Sideris, M.G., 1985. A fast Fourier transform method for computing terrain corrections, Manuscripta Geodaetica, 10, 66-73.

Sobh, M., Mansi, A.H., Campbell, S. \& Ebbing, J., 2019. Regional gravity field model of Egypt based on satellite and terrestrial data, Pure appl. Geophys., 176(2), 767-786.

Tenzer, R., Chen, W., Baranov, A. \& Bagherbandi, M., 2018. Gravity maps of antarctic lithospheric structure from remote-sensing and seismic data, Pure appl. Geophys., 175(6), 2181-2203. 
Tschirhart, P., Morris, W.A., Mims, J. \& Ugalde, H., 2019. Applying laterally varying density corrections to ground gravity and airborne gravity gradiometry data: a case study from the Bathurst Mining Camp, Can. J. Earth Sci., 56(5), 493-503.

Tsoulis, D., 2001. Terrain correction computations for a densely sampled DTM in the Bavarian Alps, J. Geod., 75(5-6), 291-307.

Tsoulis, D., Novák, P. \& Kadlec, M., 2009. Evaluation of precise terrain effects using high-resolution digital elevation models, J. geophys. Res., 114(B2), B02404. doi:10.1029/2008JB005639

Tsoulis, D.V., 1998. A combination method for computing terrain corrections, Phys. Chem. Earth, 23(1), 53-58.

Tziavos, I.N. \& Featherstone, W.E.(2001) First results of using digital density data in gravimetric geoid computation in Australia. in Gravity, Geoid and Geodynamics 2000. International Association of Geodesy Symposia, Vol 123, pp. 335-340, ed. Sideris, M.G., Springer, doi:10.1007/978-3662-04827-6_56.

Tziavos, I.N. \& Sideris, M.G., 2013. Topographic reductions in gravity and geoid modelling. in Geoid Determination. Lecture Notes in Earth System
Sciences, Vol 110, pp. 337-400, eds Sansò, F. \& Sideris, M.G., Springer. https://doi.org/10.1007/978-3-540-74700-0_8

Tziavos, I.N., Sideris, M.G. \& Suenkel, H., 1996. The effect of surface density variations on terrain modelling-A case study in Austria,in Techniques for Local Geoid Determination. Report 96(2), pp 99-110, eds Tziavos, I.N. \& Vermeer, M., Finnish Geodetic Institute, Masala.

Uwiduhaye, J.d'A, Mizunaga, H. \& Saibi, H., 2018. Geophysical investigation using gravity data in Kinigi geothermal field, northwest Rwanda, $J$. Afr. Earth Sci., 139, 184-192.

Yamazaki, D. et al., 2017. A high-accuracy map of global terrain elevations, Geophys. Res. Lett., 44(11), 5844-5853.

Yang, M., Hirt, C., Tenzer, R. \& Pail, R., 2018. Experiences with the use of mass-density maps in residual gravity forward modelling, Stud. Geophys. Geod., 62(4), 596-623.

Zahorec, P., Papčo, J., Vajda, P. \& Szabó, S., 2019. High-precision local gravity survey along planned motorway tunnel in the Slovak Karst, Contrib. Geophys. Geod., 49(2), 207-227.

\section{A P PENDIX}

Table A1. TC computation using FFT and strategies used to account for convergence and truncation.

\begin{tabular}{|c|c|c|c|}
\hline Reference & Order of TC & Remarks / Critique & $\begin{array}{l}\text { Area / DEM resolution / } \\
\max \Delta \mathrm{H}\end{array}$ \\
\hline \multicolumn{4}{|l|}{ FFT alone } \\
\hline Forsberg (1985) & 1 & $\begin{array}{l}\text { Terrain slopes near the computation point are assumed to be } \\
\text { small. No discussion on the convergence of the series. }\end{array}$ & $\begin{array}{c}9 \mathrm{~km} \times 9 \mathrm{~km} / 100 \mathrm{~m} \times \\
100 \mathrm{~m} / 608 \mathrm{~m} \\
1^{\circ} \times 1^{\circ} / 0.5^{\prime} \times 0.5^{\prime} / 700 \\
\mathrm{~m}\end{array}$ \\
\hline Sideris (1985) & 1 & $\begin{array}{l}\text { Slope considered are much smaller than } 45^{\circ} \text {. Discussed more } \\
\text { on the edge effect and windowing. No discussion on the } \\
\text { convergence of the series. }\end{array}$ & $\begin{array}{c}28 \mathrm{~km} \times 36 \mathrm{~km} / 1 \mathrm{~km} \times 1 \\
\mathrm{~km} / 2079 \mathrm{~m}\end{array}$ \\
\hline $\begin{array}{l}\text { Harrison \& } \\
\text { Dickinson (1991) }\end{array}$ & 4 & $\begin{array}{l}\text { Discussed importance of the generally neglected } 4^{\text {th }} \text { order } \\
\text { term in the FFT solution of TC. The study area is perhaps not } \\
\text { rugged enough. }\end{array}$ & $6^{\prime} \times 6^{\prime} / 6^{\prime \prime} \times 6^{\prime \prime} / 1200 \mathrm{~m}$ \\
\hline Li \& Sideris (1994) & 3 & $\begin{array}{l}\text { FFT method for mass-line and mass-prism models is derived. } \\
\text { Introduced a regularization parameter ' } \alpha \text { ' for fast convergence } \\
\text { of the TC solution. However, convergence still cannot be } \\
\text { promised. }\end{array}$ & $\begin{array}{c}5^{\circ} \times 10^{\circ} / 0.5^{\prime} \times 1^{\prime} / 3573 \\
\mathrm{~m}\end{array}$ \\
\hline \multirow[t]{2}{*}{$\begin{array}{l}\text { Kirby \& Featherstone } \\
\text { (1999) }\end{array}$} & 1 & $\begin{array}{l}\text { On obtaining spikes in the computed TC using 9" DEM (due } \\
\text { to anomalous gradients (Kirby \& Featherstone } 2001 \text { )), the } \\
\text { averaged DEM with } 27 \text { " resolution was used for } \\
\text { re-computation of the TC. Convergence is not discussed. }\end{array}$ & $\begin{array}{c}\text { Australia / 9" } \times 9 " / \\
2217.18 \mathrm{~m}\end{array}$ \\
\hline & & & $\begin{array}{c}\text { Australia / } 27 " \times 27 " / \\
2162.26 \mathrm{~m}\end{array}$ \\
\hline $\begin{array}{l}\text { Kirby \& Featherstone } \\
(2002)\end{array}$ & 1 & $\begin{array}{l}\text { TC computed with a refined national DEM. No discussion on } \\
\text { convergence. }\end{array}$ & Australia / 9" $\times 9 " / 2244 \mathrm{~m}$ \\
\hline $\begin{array}{l}\text { McCubbine et al. } \\
\text { (2017) }\end{array}$ & 1 & $\begin{array}{l}\text { TC values were removed for the computation points where } \\
\text { gradient exceeds } 45^{\circ} \text {. Gradient computed in specific directions } \\
\text { only. Cannot guarantee convergence at all points. }\end{array}$ & $\begin{array}{c}\text { Australia / 1" } \times 1 " / 2291.3 \\
\mathrm{~m}\end{array}$ \\
\hline \multicolumn{4}{|l|}{ Space-FFT combined } \\
\hline Tsoulis (1998) & 3 & $\begin{array}{l}\text { To check the violation of convergence criterion, slopes were } \\
\text { computed only in N-S and E-W directions. Also, the } \\
\text { convergence of the FFT method was analysed by varying the } \\
\text { inner radius (brute-force method). Use of the brute-force } \\
\text { method may not guarantee convergence. }\end{array}$ & $\begin{array}{c}15 \mathrm{~km} \times 20 \mathrm{~km} / 50 \mathrm{~m} \times \\
50 \mathrm{~m} / 1450 \mathrm{~m}\end{array}$ \\
\hline Tsoulis (2001) & 3 & $\begin{array}{l}\text { Extended Tsoulis (1998) with different methods for the inner } \\
\text { zone TC computation. Brute-force method applied to check } \\
\text { the convergence criterion and to analyse the effect of inner } \\
\text { zone. }\end{array}$ & $\begin{array}{c}15 \mathrm{~km} \times 20 \mathrm{~km} / 50 \mathrm{~m} \times \\
50 \mathrm{~m} / 1450 \mathrm{~m}\end{array}$ \\
\hline
\end{tabular}


Table A1. Continued

\begin{tabular}{|c|c|c|c|}
\hline Reference & Order of TC & Remarks / Critique & $\begin{array}{c}\text { Area / DEM resolution / } \\
\max \Delta \mathrm{H}\end{array}$ \\
\hline Huang (2012) & 1 & $\begin{array}{l}\text { Defined the inner zone with a grid of } 3 \times 3 \text { cells around the } \\
\text { computation point. The inner zone being } 1.5 \text { times greater } \\
\text { than maximum height difference, convergence is guaranteed. } \\
\text { But, the truncation limit for the FFT solution is not discussed. } \\
\text { The study area is very plain. }\end{array}$ & $\begin{array}{c}0.346^{\circ} \times 0.316^{\circ} / 3^{\prime \prime} \times 3^{\prime \prime} \\
80 \mathrm{~m}\end{array}$ \\
\hline Gomez et al. (2013) & 1 & $\begin{array}{l}\text { Inner zone computations are done with 3" DEM. For outer } \\
\text { zone, } 3 \text { " DEM was averaged to } 30 \text { ". Lower resolution DEM } \\
\text { was used to circumvent the converging criterion (cf. Kirby \& } \\
\text { Featherstone 1999). }\end{array}$ & $\begin{array}{c}\sim 2.5^{\circ} \times 3.5^{\circ} / 3^{\prime \prime} \times 3^{\prime \prime} / \\
2500 \mathrm{~m}\end{array}$ \\
\hline Capponi et al. (2018) & 2 & $\begin{array}{l}\text { The study focused on the inner zone TC computation. } \\
\text { Suggested to define the inner zone with a distance of a few } \\
\text { kilometres from the computation point. May not guarantee } \\
\text { convergence. }\end{array}$ & $\begin{aligned} 2^{\circ} \times 2^{\circ} / 3^{\prime \prime} \times 3^{\prime \prime} / 6500 \mathrm{~m} \\
0.83^{\circ} \times 0.83^{\circ} / 3^{\prime \prime} \times 3^{\prime \prime} / \\
2887 \mathrm{~m}\end{aligned}$ \\
\hline \multicolumn{4}{|l|}{ Others } \\
\hline Martinec et al. (1996) & 5 & $\begin{array}{l}\text { The main conclusion was that the solution will diverge if the } \\
\text { height difference of the points is larger than the distance } \\
\text { between them and if the height difference is smaller than the } \\
\text { distance between the points, the solution will converge. The } \\
\text { truncation limit to be used in order to secure a convergent } \\
\text { solution is not generalized. }\end{array}$ & $\begin{array}{l}\text { Considered two points with } \\
\text { hypothetical heights and } \\
\text { distances between them. }\end{array}$ \\
\hline
\end{tabular}

